\title{
Anticoagulation therapy: patients attitude, knowledge, and concerns regarding their effects on the international normalized ratio (INR) in Saudi Arabia.
}

\author{
Fahad I Al-Saikhan', Mohamed A Abd-Elaziz ${ }^{2 *}$, Rehab H. Ashour², Taimour Langaee ${ }^{3}$ \\ ${ }^{1}$ Department of Clinical Pharmacy, College of Pharmacy, Prince Sattam Bin Abdulaziz University, Al-Kharj, Saudi \\ Arabia \\ ${ }^{2}$ Department of Clinical Pharmacology, Mansoura University, Egypt \\ ${ }^{3}$ Department of Pharmacotherapy and Translational Research at the University of Florida (UF) College of Pharmacy, \\ USA
}

\begin{abstract}
Introduction: Thoughtful evaluation of patients' knowledge, satisfaction, and concerns in Anticoagulation clinics will help to understand areas of improvement. Our study aimed to examine patients' drug knowledge, satisfaction and concerns with provided anticoagulation services.

Patients and methods: We designed our study as a cross-sectional survey that was developed and conducted in a regional anticoagulation clinic with good number of patients. Two hundred sixty eight were recruited in the survey. Patients' warfarin refill records and time within the therapeutic INR range were retrieved from hospital databases.

Results: Adequate knowledge of warfarin-food and warfarin-drug interactions was lacking in about $50 \%$ of patients. Satisfaction with provided service was not optimal, Concerns associated with warfarin was bothersome to many patients due to possible drug-drug interactions $(\mathbf{4 1 . 4 2 \%})$, missed doses impact $(29.10 \%)$, adverse drug reactions $(\mathbf{2 9 . 8 5 \%})$. All of which might lead to unfavorable consequences. Higher satisfaction was associated with better knowledge $(r=0.27, p=0.001)$ and fewer concerns $(\mathrm{rs}=-0.26, \mathrm{p}=\mathbf{0 . 0 0 2})$. Improved drug related knowledge and higher satisfaction were positively reflected in these patients' attitude toward drug use compliance in knowledge $(\mathrm{rs}=\mathbf{0 . 2 3}, \mathrm{p}=\mathbf{0 . 0 1})$ and satisfaction ( $r s=0.19, p=0.041)$. Eventually, good INR control was shown more with better knowledge, higher satisfaction, and better warfarin adherence $(p=0.004,0.03,0.04$ and 0.004 , respectively).

Conclusion: There is a deficit in patients' knowledge and satisfaction with warfarin therapy. Such deficits lifted the threshold of concerns with warfarin use and negatively affected INR control.
\end{abstract}

Keywords: Warfarin therapy, Knowledge, Satisfaction, INR control.

Accepted on January 23, 2018

\section{Introduction}

Chronic anticoagulation management for thromboembolic events is mainly achieved by oral warfarin therapy for decades. This is attributed mainly to its ability to alter the coagulation cascade therefor improves the International Normalized Ratio (INR) in order to prevent further clot formation in patient experiencing higher risk [1]. INR being above the normal levels might produce hemorrhage if excessive; whereas low INR values might but patients at risk of additional clotting events [2-4]. Warfarin, therefor, must be used with tight follow up to keep INR values within the desirable levels.

Achieving anticoagulation effect after warfarin administration is a multifactorial process. Inter-individual response to the drug varies due to presence of genetic sequence variant that may require several dose changes throughout the course of therapy to obtain steady INR levels [5]. Patient counselling and education will improve response to INR; therefore, achieving desired outcomes. Several studies was able to confirm that better patient awareness of their therapy will eventually improve outcomes (good INR control) [6,7]. Therefore, obtaining complete patient information is crucial for assessing lack of warfarin knowledge and patient's satisfaction with therapy that shown to worsen medication compliance and compromise INR control. By understanding the deficits and areas of required improvement, intended interventions can be formulated then implemented in overall patient care.

This study was conducted to recognize patients' knowledge and satisfaction with warfarin therapy. Our second aim was to evaluate their effect on INR control in Saudi Arabian patients. 


\section{Study Methods}

\section{Patient recruitment and data collection}

This study was a cross-sectional survey of patients prescribed warfarin for the management of thromboembolic events (chronic use) at a busy regional anticoagulation clinic. The survey was conducted for a period of six months (December 2016-May 2017). For a study power of 0.80 , we aimed to recruit at least 253 patients. Significance level was set at 5\%. All patients were adults, male or female, able to read, on warfarin therapy for any thromboembolic event, and signed the consent form to participate. Study was approved by ethical committee prior to commencement.

Adherence to therapy was obtained from available Health Information System (HIS) database (pharmacy module) which was reviewed for the past 9 months for doses, supplied quantities, and refill regularity in addition to patients' responses to questionnaire. Warfarin adherence then was computed by Refill Compliance Rate "RCR" from the formula ((sum of quantity dispensed over interval/quantity to be taken per day) $\times 100$ )/number of days in interval between first and last refill [8]. For INR control history as being $90 \%$ or higher of the time in target therapeutic range, we reviewed the medical laboratory module database in the HIS.

\section{Survey questionnaire}

Several questionnaires were reviewed and developed on the bases of previous publications [9-11]. In addition to available patient counselling materials that are usually provided to the new patients in the anticoagulation clinic, we developed and used a four step questionnaire that is detailed in the supplementary materials (Warfarin Questionnare.docx). Briefly, step one included the patients' demographics and characteristics; step two involved questions on patients' knowledge of warfarin therapy; step three composed of a satisfaction scale regarding the care and services in the anticoagulation clinic; step four was 10 points of concerns regarding warfarin therapy. Before commencing the study, expert opinions and potential patients comment were obtained on the formulated questionnaire and taken in consideration.

\section{Statistical analysis}

All statistical assessment and analysis were carried out with IBM SPSS 24.0 (SPSS Inc., Chicago, IL). Data were stated as percentage or mean $\pm \mathrm{SD}$ as appropriate. Independent samples t-test, Pearson's Chi-Square test, and Mann Whitney U test were used as required. Pearson's or Spearman's correlation analysis was also used to evaluate the correlation between drug therapy concerns with knowledge and satisfaction with the service scores. Same analyses were applied to examine the correlation of warfarin refill regularity with drug knowledge, service satisfaction, and drug use concerns scores. Significance was defined by a $\mathrm{p}$ value $<0.05$.

\section{Results}

\section{Demographic data}

Survey questionnaire was introduced to around 320 subjects. Only 268 accepted to participate (83.8\%). Table 1 and Figure 1 illustrate study subjects individual differences. Male and females were almost equal among all respondents $(51.12 \%$ vs. $48.88 \%$, respectively). Patients had a mean \pm SD age of 55.03 $\pm 8.85 \mathrm{y}$. It was noted that patients respondent with inadequate INR control (less than 90\%) included 67.54\%. More than one third $(37.69 \%)$ of respondent had university or high educational level, Figure 2 and Table 2. Warfarin refill regularity mean \pm SD of $90.0 \pm 17.8 \%$.

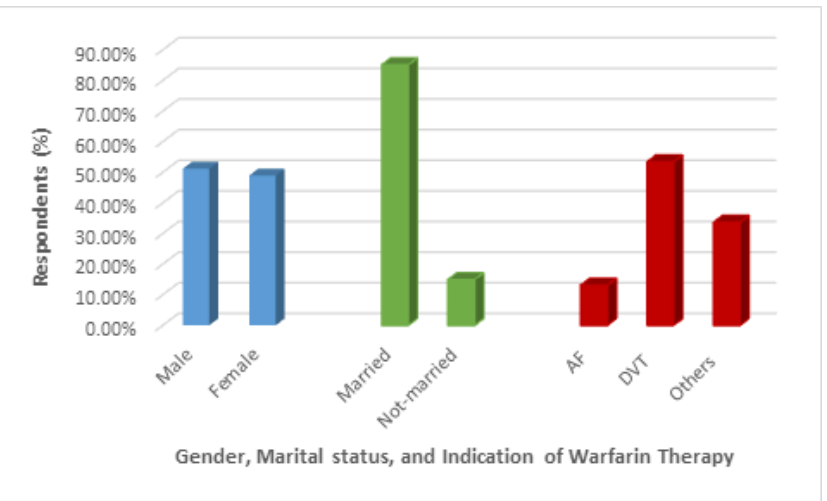

Figure 1. The percent distribution of gender, marital status, and indication of warfarin therapy among the respondents.

\section{Educational level}

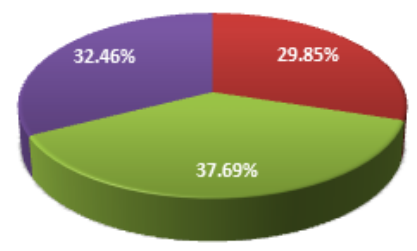

No school or primary ⿶Secondary or High school QUniversity level or higher

Figure 2. The percent distribution of educational level among the respondents.

Patient satisfaction with the provided service was mean \pm SD score of $20 \pm 3.37$. Notably, about $95 \%$ of surveyed patients felt happy with care providers and $49.6 \%$ of patients were not satisfied about the provided service when it comes to waiting time to see care provider. Table 3 illustrates all given response in this domain.

Concerns related to warfarin therapy and possible associated risk was of median 1 with more results toward the high end. It was obvious and expected to have more concerns about the drug therapy from new patients than those who were taking it for longer period $(\mathrm{rs}=-0.23, \mathrm{p}=0.004)$. Chronic patients as well as newer ones all together (39.7\%) indicated no concerns with 
Anticoagulation therapy: patients attitude, knowledge, and concerns regarding their effects on the international normalized ratio (INR) in Saudi Arabia

warfarin use. This may explain the low knowledge of drug and possible side effects while using it. All results in this category are shown in Figure 3.

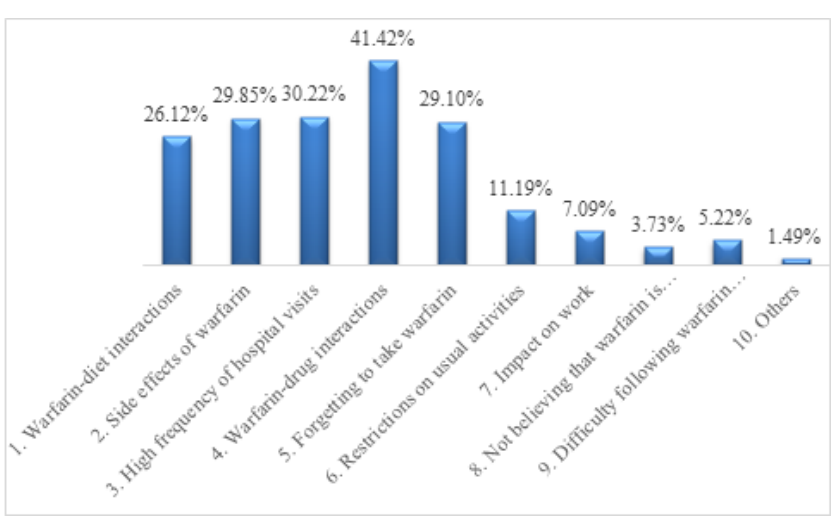

Figure 3. The percent distribution of warfarin therapy concerns among the respondents.

It is worth mentioning that educated patients and elderlies gave favorable responses in satisfaction related questions. Drug related knowledge $(r=0.27, p=0.001)$ and drug use concerns $(\mathrm{rs}=-0.26, \mathrm{p}=0.002)$. This was positively reflected in these patients attitude towards drug use compliance in both categories (knowledge $\mathrm{rs}=0.23, \mathrm{p}=0.01$, and satisfaction $\mathrm{rs}=0.19, \mathrm{p}=0.041$ ). Eventually, good INR control was shown more with better knowledge, higher satisfaction, fewer concerns, and better warfarin adherence $(\mathrm{p}=0.004,0.03,0.04$ and 0.004 , respectively).

Table 1. Demographic data and patient characteristics.

\begin{tabular}{lll}
\hline Characteristics & \multicolumn{2}{l}{ Respondents } \\
\cline { 2 - 3 } & $(\mathbf{n = 2 6 8 )}$ & $\mathbf{( \% )}$ \\
\hline Within target INR in the past 3 months & & \\
\hline$<90(\%)$ & 181 & $67.54 \%$ \\
\hline$\geq 90(\%)$ & 87 & $32.46 \%$ \\
\hline & Mean \pm SD & \\
\hline Age $(y)$ & 55.03 & 8.85 \\
\hline Duration for taking warfarin $(y)$ & 5.3 & 4.9 \\
\hline
\end{tabular}

Table 2. Issues on patients' knowledge of warfarin treatment $(n=268)$.

\begin{tabular}{|c|c|c|}
\hline Item & Correct responses, $\mathbf{n}$ & $\%$ \\
\hline \multicolumn{3}{|l|}{ Warfarin's adverse effects } \\
\hline Symptoms of bleeding & 201 & $75.00 \%$ \\
\hline Frequency of monitoring signs of bleeding & 150 & $55.97 \%$ \\
\hline Association between warfarin dosage, INR control, and subsequent clinical complication & 135 & $50.37 \%$ \\
\hline Impact of warfarin on intramuscular injections & 92 & $34.33 \%$ \\
\hline \multicolumn{3}{|l|}{ Warfarin administration } \\
\hline Color and number of daily warfarin tablets prescribed & 208 & $77.61 \%$ \\
\hline Actions to take if a warfarin dose is missed & 185 & $69.03 \%$ \\
\hline Target INR range & 175 & $65.30 \%$ \\
\hline \multicolumn{3}{|l|}{ Warfarin-drug interactions } \\
\hline Consulting doctors when starting a new medicine & 220 & $82.09 \%$ \\
\hline Medicines that interact with warfarin & 130 & $48.51 \%$ \\
\hline \multicolumn{3}{|l|}{ Warfarin-diet interactions } \\
\hline Importance of keeping a consistent diet & 196 & $73.13 \%$ \\
\hline Food that interacts with warfarin & 140 & $52.24 \%$ \\
\hline
\end{tabular}

Patient knowledge was analysed using independent samples t-test and Mann Whitney $\mathrm{U}$ test as appropriate.

Table 3. Distribution of responses to each statement in the satisfaction scale $(n=268)$.

\begin{tabular}{|c|c|c|c|c|c|c|c|c|c|}
\hline \multirow{2}{*}{$\begin{array}{l}\text { Statements } \\
\text { 1. The care provider at the warfarin clinic can give you useful and } \\
\text { sufficient instructions on your treatment. }\end{array}$} & \multicolumn{2}{|c|}{ Strongly agree $\mathbf{n}(\%)$} & \multicolumn{2}{|c|}{ Agree n (\%) } & \multicolumn{2}{|c|}{ Neutral n (\%) } & \multicolumn{2}{|c|}{ Disagree n (\%) } & $\begin{array}{l}\text { Strongly disagree } \\
\text { n (\%) }\end{array}$ \\
\hline & 91 & $33.96 \%$ & 160 & $59.70 \%$ & 7 & $2.61 \%$ & 6 & $2.24 \%$ & $1.49 \%$ \\
\hline
\end{tabular}




\begin{tabular}{|c|c|c|c|c|c|c|c|c|c|c|}
\hline $\begin{array}{l}\text { 2. You have been given enough time to discuss therapy with the } \\
\text { staff your visits. }\end{array}$ & 88 & $32.84 \%$ & 162 & $60.45 \%$ & 11 & $4.10 \%$ & 5 & $1.87 \%$ & 2 & $0.75 \%$ \\
\hline 3. The staff at the clinic are friendly. & 125 & $46.64 \%$ & 132 & $49.25 \%$ & 7 & $2.61 \%$ & 2 & $0.75 \%$ & 2 & $0.75 \%$ \\
\hline $\begin{array}{l}\text { 4. Since you began your treatment at this hospital, you have felt } \\
\text { reassured about your warfarin treatment. }\end{array}$ & 77 & $28.73 \%$ & 161 & $60.07 \%$ & 20 & $7.46 \%$ & 10 & $3.73 \%$ & 0 & $0.00 \%$ \\
\hline $\begin{array}{l}\text { 5. Since you began your treatment at this clinic, your blood INR } \\
\text { results have been better controlled. }\end{array}$ & 68 & $25.37 \%$ & 147 & $54.85 \%$ & 41 & $15.30 \%$ & 11 & $4.10 \%$ & 1 & $0.37 \%$ \\
\hline $\begin{array}{l}\text { 6. You are satisfied with the frequency of your appointments at this } \\
\text { hospital for your warfarin follow ups. }\end{array}$ & 65 & $24.25 \%$ & 144 & $53.73 \%$ & 42 & $15.67 \%$ & 16 & $5.97 \%$ & 1 & $0.37 \%$ \\
\hline $\begin{array}{l}\text { 7. You are satisfied with your waiting time in the warfarin clinic to } \\
\text { see the care provider. }\end{array}$ & 35 & $13.06 \%$ & 100 & $37.31 \%$ & 78 & $29.10 \%$ & 45 & $16.79 \%$ & 10 & $3.73 \%$ \\
\hline
\end{tabular}

Patient satisfaction was analysed using independent samples t-test and Mann Whitney $U$ test as appropriate.

\section{Discussion}

Our study confirmed that many warfarin patients even those of chronic use are not likely to have more than moderate knowledge about the drug. It was also noted that our patients' knowledge deficit was not too much different from other patients in published studies as Davis et al. study that reported poor anticoagulant control, knowledge, and compliance to warfarin therapy [12]. Knowledge deficit was mainly in warfarin associated food and drug interactions. As we know about warfarin precautions, its effect will change depending on patient intake and other medication use [13,14].

Similarly, less educated patients and those ranked in upper age groups had less (poor) knowledge on warfarin therapy that affect the desired outcome. This finding was also shown in previously published paper that demonstrated old age as a significant factor underlying poor anticoagulant knowledge [7]. Many factors might have played a role in this trend but could be attributed to cognitive limitations despite educational programs and distributed materials for all new warfarin-treated patients. We believe that more anticoagulation clinic staff must have a positive response from patients to confirm their comprehension of any given instructions. In addition, it would also be recommended to schedule older patients for general warfarin session periodically in order to improve their knowledge on their treatment goals. Use of various educational methods, e.g. audiovisual materials or special educators, could yield a better outcome. It is understood that older patients are usually come with polypharmacy as a result of their multiple chronic conditions. Patients' health might be at risk on top of lacking better INR control [14].

As shown in our findings, patients' satisfaction with provided service was not optimal but rather moderate. The main concern was the extended waiting time to see the healthcare provider at the clinic. As it is the case worldwide, lack of trained healthcare workers leads to less patient access to intended care [15]. In our study particularly, more trained staff were recruited to overcome this concern. Pharmacists are proven to administer an outstanding patient care in multidiscipline settings. Increasing number of staff in anticoagulation clinics will eventually improve patient communication leading to better INR control.

Surveyed patients demonstrated their worries about possible drug interaction with other drugs or diet. Worries also shown regarding adverse drug events. We believe these were valid concerns and could be alleviated with better educational programs and improved patient-clinic communication. Drug use adherence (compliance) with prescriptions and clinic instructions will reduce possible adverse events as a result of various interactions or missed doses. Several patients might afford and could be willing to use home warfarin testing which will provide assurance to INR levels in addition to reducing clinic visits that was of another concern to few patients [15]. When providing optimal education and required training to warfarin patient, some patient might be able to self-monitor their therapy. This was also introduced in previous studies assuring more INR control, less clinic visits, and improved patient safety $[16,17]$. Home INR monitoring might be a stimulus for tighter control, less off therapeutic range values, and happier patients.

The ultimate goal of keeping patient within desired therapeutic range is to prevent associated risk for off-range values. INR levels are results of human body reaction to warfarin intake which is affected by many environmental or genetic factors. Patient diet and eating habits are easily manageable with directed educational programs that will eventually produce a better INR control. On the other hand, genetic factors (presence of genetic sequence variants, VKORC1 or CYP2C9), may lead to patient over-reaction to regular doses of warfarin (average dose). In such cases, usual anticoagulation clinic follow-ups may not produce anticipated results $[18,19]$. Patient reaction to warfarin due to genetic differences cannot be manipulated.

Better INR control was noted more in patients' categories with better knowledge, higher satisfaction, less warfarin use concerns. As mentioned earlier clinic conducted programs are able to positively affect these categories producing desirable INR values.

In conclusion, our study findings trending toward more emphasis on patient directed educational programs in 


\section{normalized ratio (INR) in Saudi Arabia}

anticoagulation clinics. There is a vast shortage in patients' knowledge and satisfaction with warfarin therapy. Such deficits lifted the threshold of concerns with warfarin use and negatively affected INR control. Drug therapy adherence correlated negatively with less knowledge, level of education, and satisfaction with provided services. All of which had produced less INR control.

In order to obtain desired INR levels in any anticoagulation clinic, one should consider all the discussed factors, establish a well-designed patient oriented educational program for warfarin users focusing on improving drug use knowledge, alleviating therapy concerns, not to disregard continuous evaluation of anticoagulation clinic operation, introducing more trained staff, and soliciting patients' opinions on every visit.

\section{Conflict of Interest Statement}

Authors revealed no conflict of interest.

\section{Acknowledgement}

The authors deeply thankful and indebted to the Scientific Research Deanship of Prince Sattam Bin Abdulaziz University, Al-kharj, Saudi Arabia (Project no. 2016/03/6335), for providing financial support.

\section{References}

1. Ansell J, Hirsh J, Poller L, Bussey H, Jacobson A, Hylek E. The pharmacology and management of the vitamin $\mathrm{K}$ antagonists: the seventh ACCP conference on antithrombotic and thrombolytic therapy. Chest 2004; 126 : 204-233.

2. Hylek EM, Go AS, Chang Y, Jensvold NG, Henault LE, Selby JV. Effect of intensity of oral anticoagulation on stroke severity and mortality in atrial fibrillation. N Engl J Med 2003; 349: 1019-1026.

3. Levine MN, Raskob G, Beyth RJ, Kearon C, Schulman S. Hemorrhagic complications of anticoagulant treatment: the seventh ACCP conference on antithrombotic and thrombolytic therapy. Chest 2004; 126: 287-310.

4. Merli GJ, Tzanis G. Warfarin: what are the clinical implications of an out-of-range- therapeutic international normalized ratio? J Thromb Thrombolysis 2009; 27: 293-299.

5. Krynetskiy E, McDonnell P. Building individualized medicine: prevention of adverse reactions to warfarin therapy. J Pharmacol Exp Ther 2007; 322: 427-434.

6. Wang Y, Kong MC, Ko Y. Comparison of three medication adherence measures in patients taking warfarin. $\mathrm{J}$ Thromb Thrombolysis 2013; 36: 416-421.

7. Tang EO, Lai CS, Lee KK, Wong RS, Cheng G, Chan TY. Relationship between patients warfarin knowledge and anticoagulation control. Ann Pharmacother 2003; 37: 34-39.
8. Sturgess IK, Hughes CM, McElnay JC. Refill compliance rates: evidence for use as an outcome measure in practicebased research. Pharmaceut J 2000; 265: 35.

9. Hess LM, Raebel MA, Conner DA, Malone DC. Measurement of adherence in pharmacy administrative databases: a proposal for standard definitions and preferred measures. Ann Pharmacother 2006; 40: 1280-1288.

10. Smith MB, Christensen N, Wang S, Strohecker J, Day JD, Weiss JP. Warfarin knowledge in patients with atrial fibrillation: implications for safety, efficacy, and education strategies. Cardiology 2010; 116: 61-69.

11. Wang Y, Kong MC, Lee LH, Ng HJ, Ko Y. Knowledge, satisfaction, and concerns regarding warfarin therapy and their association with warfarin adherence and anticoagulation control. Thromb Res 2014; 133: 550-554.

12. Davis NJ, Billett HH, Cohen HW, Arnsten JH. Impact of adherence, knowledge, and quality of life on anticoagulation control. Ann Pharmacother 2005; 39: 632-636.

13. Kurnik D, Loebstein R, Rabinovitz H, Austerweil N, Halkin H, Almog S. Over-the- counter vitamin K1containing multivitamin supplements disrupt warfarin anticoagulation in vitamin K1-depleted patients. A prospective, controlled trial. Thromb Haemost 2004; 92: 1018-1024.

14. Juurlink DN. Drug interactions with warfarin: what clinicians need to know? CMAJ 2007; 177: 369-371.

15. Völler H, Dovifat C, Glatz J, Körtke H, Taborski U, Wegscheider K. Self-management of oral anticoagulation with the IN Ratio system: impact of a structured teaching program on patients knowledge of medical background and procedures. Eur J Cardiovasc Prev Rehabil 2004; 11: 442-447.

16. Morsdorf S, Erdlenbruch W, Taborski U, Schenk JF, Erdlenbruch K, Novotny-Reichert G. Training of patients for self-management of oral anticoagulant therapy: standards, patient suitability, and clinical aspects. Semin Thromb Hemost 1999; 25: 109-115.

17. Kulinna W, Ney D, Wenzel T, Heene DL, Harenberg J. The effect of self-monitoring the INR on quality of anticoagulation and quality of life. Semin Thromb Hemost 1999; 25: 123-126.

18. Aquilante CL, Langaee TY, Lopez LM, Yarandi HN, Tromberg JS, Mohuczy D. Influence of coagulation factor, vitamin $\mathrm{K}$ epoxide reductase complex subunit 1 , and cytochrome P450 2C9 gene polymorphisms on warfarin dose requirements. Clin Pharmacol Ther 2006; 79: 291-302.

19. Sconce EA, Khan TI, Wynne HA, Avery P, Monkhouse L, King BP. The impact of CYP2C9 and VKORC1 genetic polymorphism and patient characteristics upon warfarin dose requirements: proposal for a new dosing regimen. Blood 2005; 106: 2329-2333. 


\section{*Correspondence to}

Mohamed A Abd-Elaziz

Department of Clinical Pharmacology

Mansoura University

Egypt 